\title{
Technology for soil restoration after contamination with well fluids on the territory of oil production land
}

\author{
Anna Chernova ${ }^{1 *}$, Anton $\mathrm{Kosov}^{2}$, Denis Ivasenko ${ }^{2,3}$, and Alexei $\mathrm{Kitaev}^{4}$ \\ ${ }^{1}$ National Research Tomsk Polytechnic University, Lenin Ave. 30, 634050, Tomsk, Russia \\ ${ }^{2}$ LLC Darwin-Service, Kartashova Str. 22, 634012, Tomsk, Russia \\ ${ }^{3}$ National Research Tomsk State University, Lenin Ave. 36, 634050 Tomsk, Russia \\ ${ }^{4}$ LLC Grinstroyservis, Shebalino, Sovetskaya Str. 29, 649220, Altai Republic, Russia
}

\begin{abstract}
A technology had been developed for the restoration of soils contaminated with well fluids, using the example of the Novogodneye oil field and gas condensate field in the Yamalo-Neninsky district. The developed technology had been tested for 2 years. The optimal agrotechnical and technical-technological methods of soil restoration were selected. It was established that to achieve the maximum effect, it is recommended to carry out reclamation in 2 stages: creating drainage channels with the introduction of calcium-containing reagents in early spring, milling the soil and sowing grass mixtures in late autumn.
\end{abstract}

\section{Introduction}

The main oil and gas reserves of Russia are in the northern part of the West Siberian part of the Yamalo-Neninsky district. There is maintains 133 oil fields, which account for $14.54 \%$ of all oil reserves of the country [1]. Yearly in the territories of oil fields occur the spills of the highly mineralized liquids, while transported through the pipelines. In this regard, the solution to the problem of soil salinization here is one of the most urgent. The oilcontaining fluid includes hydrocarbons and highly mineralized water with salts dissolved in it, is characterized by a high fluidity. In emergencies on the pipelines the transported well fluid instantaneously penetrates deep into the soil layers, which makes it practically impossible to collect the pollutant from the surface [2-4]. The processes of natural restoration of fertility proceed extremely sluggish due to low average annual temperatures, a short summer period and few of precipitation during the year. Thus, reclamation of contaminated soil requires an integrated approach with consideration of all possible environmental consequences [5].

To date, the techniques for reclamation of saline soil are primarily aimed at collecting pollutants on soil or ripping a soil-absorbing complex using special vehicles. The mechanical treatment of soil requires large costs and leads to rapid deterioration of transport. After that, the water permeability of soil is reduced. Desalination as a result of

\footnotetext{
*Corresponding author: achernova2017@gmail.com
} 
the destruction of hydrocarbons is routinely accompanied by the produce of water-soluble salts, which enhances the degree of salinization and leads, in addition to oil pollution, to a soil resalting [5-6]. Summarizing up, it is necessary to develop the technologies for soil remediation, aimed both at solving the problem of desalination of the soil and at stimulating the processes of microbiological cleaning of the soil from oil. Thus, the problem of greening the oil industry, in particular the restoration of natural landscapes, is relevant and requires an integrated approach.

This work aims to develop a technology for desalination of the area of the oil production complex of the Yamalo-Nenets region using the integrated methods.

\section{Experimental part}

\subsection{Methods and samples}

Specialists of LLC Grinstroyservis (Altai Republic, Russia), LLC TomPromTrans (Tomsk, Russia), and technologists of LLC Darwin-Service (Tomsk, Russia) tested the developed integrated technology at the experimental plot №. 99 of the Novogodneye oil field of the Yamal-Nenets Autonomous District of the NNG Gazprom field. The climate in the YamalNenets region is temperate continental [7] with an average annual temperature of $6.7^{\circ} \mathrm{C}$, rainfall $-550 \mathrm{~mm}$, with a windrose of the north-east direction.

Samples were drawn at a depth of 1.5 meters to the occurrence of groundwater according to Russian State Standard: GOST № 28168-89 “The soil. Sample selection”, GOST № 17.4.3.01-83 "Protection of Nature. The soil. General sampling requirements"; GOST № 53123-2008 “Soil quality. Sample selection. Part 5. Guidelines for the study of urban and industrial sites for soil pollution". Samples were taken pointwise from several wells in the area at depths of $0-30 \mathrm{~cm}, 30-60 \mathrm{~cm}, 60-100 \mathrm{~cm}, 100-150 \mathrm{~cm}$.

Analyses were carried out at the Regional Committee for Environmental Protection and Nature Management (Tomsk).

The concentration of petroleum products was evaluated according to Russian State Standard PND F 16.1.8-98 "Quantitative chemical analysis of soils. Methodology for measuring the mass concentration of nitrite, nitrate, chloride, fluoride, sulfate and phosphate ions in soil samples (water-soluble form) by ion chromatography", the concentration of ions in the water extract were determined according to Russian State Standard PND F 16.1.8-98; PND F16.1:2.2.22-98 "Quantitative chemical analysis of soils. The methodology for measuring the mass fraction of oil products in mineral, organogenic, organomineral soils and bottom sediments by IR spectrometry”; GOST № 326423-85 “The soil. Methods for determining the electrical conductivity, $\mathrm{pH}$ and the solid residue of the aqueous extract".

\section{Result and discussion}

Before starting work, the site study was carried out (Figure 1). The area of the experimental plot (3.8 ha) is a relatively flat elevated surface (the upland section) with a bias towards the bog (the wetland section). The major part of the upper salinized area was occupied by areas with a low degree of water cut and oppressed or dead vegetation (shrubs, grass cover). The upper bog occupied a smaller part of the territory, with a high degree of water cut, but the vegetation cover was also absent or was oppressed.

A large amount of salts contained (predominant sodium and chloride) in oil and highlysaline bottom water, enters the soil and underground water. The accumulation of ions $\mathrm{K}^{+}$, $\mathrm{Ca}^{2+}, \mathrm{Na}^{+}, \mathrm{Cl}^{-}, \mathrm{SO}_{4}{ }^{2-}$ lead to compaction and degradation of the soil cover. according to [8- 
9], water wells are flooded using water having sodium chloride composition during oil production in western Siberia. In water, the chloride anion is $99.9 \%$ of the total number of all anions, the total sodium and potassium content is $87.8 \%$ of all cations. Table 1 presents the initial soil composition of the experimental site No. 99 of the Novogodneye oil field prior to the reclamation process.

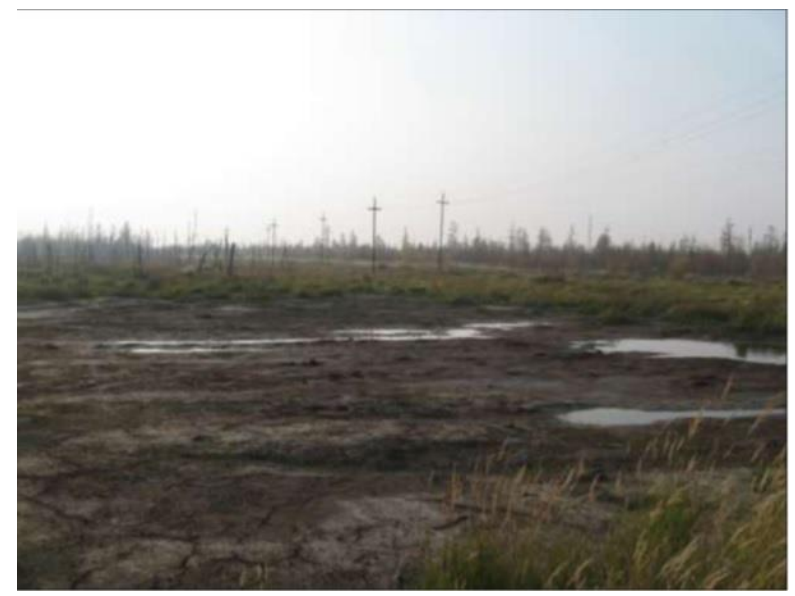

Fig. 1. Photo of the experimental plot №. 99 of the Novogodneye oil field of the Yamal-Nenets Autonomous District of the NNG Gazprom before reclamation

Based on the data of table No. 1, soils are characterized by a high content in the upper layers $(0-0.30 \mathrm{~m})$ of oil products (more than $21 \mathrm{~g} \mathrm{~kg}^{-1}$ soil), ion sodium (205 mg kg-1 soil) and anion chloride (103 $\mathrm{mg} \mathrm{kg}^{-1}$ soil) at a depth of $1.5 \mathrm{~m}$. As a result, it led to the increase an acidity soil $(\mathrm{pH}=5.5)$ at the depth. As they deepen in the soil horizons, the concentration of crude products decreases to $57 \mathrm{mg} \mathrm{kg}^{-1}$ soil at a depth of $1.0 \mathrm{~m}$. However, in the lower layers the amount of oil products increases to $459 \mathrm{mg} \mathrm{kg}^{-1}$ soil, which is due to the accumulation of reservoir emulsified oil in the soil.

Table 1. The initial content of oil products, ions of sulfate, chloride, calcium, sodium, potassium in the area of site №. 99 of the Novogodneye oil field.

\begin{tabular}{|c|c|c|c|c|c|c|c|}
\hline $\begin{array}{l}\text { Depth, } \\
\text { m }\end{array}$ & pH & $\begin{array}{c}\text { Crude } \\
\text { products, } \\
\text { mg kg-1 }^{-1}\end{array}$ & $\begin{array}{l}\text { Potassium, } \\
\text { mg kg-1 }\end{array}$ & $\begin{array}{l}\text { Calcium, } \\
\mathrm{mg} \mathrm{kg}^{-1}\end{array}$ & $\underset{\mathrm{kg}^{-1}}{\text { Sodium, mg }}$ & $\begin{array}{l}\text { Chloride, } \\
\text { mg kg }^{-1}\end{array}$ & $\begin{array}{l}\text { Sulphate, } \\
\text { mg kg }^{-1}\end{array}$ \\
\hline \multirow{2}{*}{$0-0.3$} & 7.3 & 21,973 & 17.90 & $1,558.0$ & 186.0 & 88.0 & 7.20 \\
\hline & $5.4 *$ & $<50.0^{*}$ & $19.6^{*}$ & $1,545^{*}$ & $<5.0^{*}$ & $9.8^{*}$ & $2.90 *$ \\
\hline \multirow{2}{*}{$0.3-0.6$} & 5.1 & 108.0 & $<5.0$ & $1,686.0$ & 207.0 & 269.0 & 7.90 \\
\hline & $5.9^{*}$ & $<50.0^{*}$ & $9.9^{*}$ & $1,627.0^{*}$ & $5.1^{*}$ & $10.1^{*}$ & $4.20 *$ \\
\hline \multirow{2}{*}{$0.6-1.0$} & 5.3 & 57.0 & $<5.0$ & $2,060.0$ & 252.0 & 206.0 & 2.40 \\
\hline & $5.9 *$ & $<50.0^{*}$ & $11.7^{*}$ & $2,021.0^{*}$ & $5.8^{*}$ & $15.1^{*}$ & $2.30 *$ \\
\hline \multirow{2}{*}{$1.0-1.5$} & 5.4 & 459.0 & $<5.0$ & $1,020.0$ & 260.0 & 233.0 & 4.40 \\
\hline & $6.1^{*}$ & $<50.0^{*}$ & $20.8^{*}$ & $1,872.0^{*}$ & $6.7 *$ & $20.7^{*}$ & $3.30 *$ \\
\hline
\end{tabular}

* background indicators. To determine the background state by the ion content in the soil horizons, natural undisturbed areas of the Novogodneye field with dense grass and no traces of economic activity were identified.

The predominance of sodium and chloride ions in the soil-surface complex led to a violation of plasticity, porosity, and a decrease in the filtration. At the same time, in the wet state, the soil was characterized by increased viscosity and stickiness, and in the dry state, by hardness. Probably plant growth is inhibited due to the toxic effects of chlorine ions on respiration, photosynthesis, and absorption of nitrogen and phosphorus [9-11]. 
It was shown that the sodium content in the soil adsorption complex (SAC) exceeded $10 \%$ of the total amount; therefore, in order to restore the soil layer, it is necessary to carry out reclamation in three stages. The technical stage is involved the creation of drainage channels throughout the entire site to leach excess toxic elements from the soil-suction complex. Drainage and loosening of the dense upper soil layer by repeated milling was carried out using bucket excavator. For chemical reclamation [10-14] of solonetzic soils, can be used calcium-containing compounds such as gypsum, phosphogypsum, chalk, limestone, calcium nitrate, or their mixtures.

For chemical reclamation, the amount of ameliorant was calculated based on the volumetric sodium content in the soil adsorption complex and the solubility of the ameliorant in water (Table 2) [11].

Table 2. Amount of calcium reagents added to saline areas.

\begin{tabular}{|c|c|c|c|c|}
\hline Sample & $\begin{array}{c}\text { Amount of ion Na } \mathbf{N a}^{+} \\
\text {before reclamation, } \\
\text { mg per 1000 g soil }\end{array}$ & $\begin{array}{c}\text { Amount of gypsum } \\
\left(\mathbf{C a S O}_{\mathbf{*}} \mathbf{2 H}_{\mathbf{2}} \mathbf{O}\right), \\
\text { ton per hectare }\end{array}$ & $\begin{array}{c}\text { Amount of } \\
\text { calcium nitrate } \\
\mathbf{C a}\left(\mathbf{N O}_{3}\right)_{2}, \\
\text { ton per hectare }\end{array}$ & $\begin{array}{c}\text { Amount of } \\
\text { slaked lime } \\
\mathbf{C a}(\mathbf{O H})_{2} \\
\text { ton per } \\
\text { hectare }\end{array}$ \\
\hline $\begin{array}{c}\text { № 1 } \\
(0.0-0.3 \mathrm{~m})\end{array}$ & 186.0 & 0.804 & 0.651 & 0.294 \\
\hline $\begin{array}{c}\text { № } 2 \\
(0.3-0.6 \mathrm{~m})\end{array}$ & 207.0 & 1.161 & 0.940 & 0.424 \\
\hline $\begin{array}{c}\text { № } 3 \\
(0.6-1.0 \mathrm{~m})\end{array}$ & 252.0 & 2.554 & 2.067 & 0.932 \\
\hline $\begin{array}{c}\text { № } 4 \\
(1.0-1.5 \mathrm{~m})\end{array}$ & 260.0 & 3.418 & 2.767 & 1.250 \\
\hline
\end{tabular}

For a uniform distribution of ameliorants in the soil surface layer, they were added both in dissolved form (suspension) and in dry (powder) form. The calcium-containing suspension of ameliorate was added using a pump and fire hose system. The composition of the calcium-containing suspension of the ameliorant included gypsum and calcium nitrate in a ratio of 30:70, respectively. Incorporated calcium into soil led to the displacement of sodium and the neutralization of its negative effects on SAC (table 3).

Table 3. Amount of ion $\mathrm{Na}^{+}$and degree of soil alkalinity by horizons in the site № 99 Novogodneye field before and after reclamation.

\begin{tabular}{|c|c|c|c|c|}
\hline Sample & $\begin{array}{c}\text { Amount of ion } \mathrm{Na}^{+} \\
\text {before reclamation, } \\
\text { mg per 1000 g soil }\end{array}$ & $\begin{array}{c}\text { The degree of soil } \\
\text { salinity, } \\
\text { \% from CEC }\end{array}$ & $\begin{array}{c}\text { Amount of ion } \\
\text { Na }{ }^{+} \text {after } \\
\text { reclamation, } \\
\text { mg per 1000 g } \\
\text { soil }\end{array}$ & $\begin{array}{c}\text { The degree of } \\
\text { soil salinity, } \\
\text { \% from CEC }\end{array}$ \\
\hline $\begin{array}{c}\text { № } 1 \\
(0.0-0.3 \mathrm{~m})\end{array}$ & 186.0 & 13.40 & 8.60 & 0.623 \\
\hline $\begin{array}{c}\text { № } 2 \\
(0.3-0.6 \mathrm{~m})\end{array}$ & 207.0 & 15.00 & 9.10 & 0.650 \\
\hline $\begin{array}{c}\text { № } 3 \\
(0.6-1.0 \mathrm{~m})\end{array}$ & 252.0 & 18.20 & 9.30 & 0.666 \\
\hline $\begin{array}{c}\text { № } 4 \\
(1.0-1.5 \mathrm{~m})\end{array}$ & 260.0 & 18.80 & 9.50 & 0.688 \\
\hline
\end{tabular}

As a result of technical recovery, the acidity of the medium was 6.0. Physico-chemical and biological properties of the soil were improved due to phytomelioration. Several types of plants were introduced into the soil, adapted to the data of climatic conditions that 
stimulated microbiological processes in soil. Moreover [6, 13-15] the degradation of oil products by microorganisms depends on the rate of biological nitrogen fixation. The symbiosis between hydrocarbon-oxidizing microorganisms and biological nitrogen will provide a high rate of self-healing of oil-contaminated soil. Moreover, plants adsorb the toxical salts from the soil layer, and accumulate it in biomass. Therefore, in the soil was added a complex biological product "Aborigine" (Tomsk) in an amount $20 \mathrm{~L}$ per ha and seeds of grasses such as cultivated oat (Avena sativa), ordinary barley (Hordeum vulgare), couch grass (Agropyron repens), tall begetter (Bidens vulgata), wild spin (Chenopodium album), melilot yellow (Melilotus officinalis) and melilot white (Melilotus albus).

Observations of the state of crops in field experiments in 2017 showed satisfactory results. The area of grass cover on the site was about $60 \%$. The area of grass cover on the site was about $60 \%$. However, the grass cover was not evenly distributed, from the outskirts of the site to its central parts. This can be explained by the fact that in spring the plot was flooded, and part of the grass seeds were carried away by the spring flood. Therefore, repeated measures were taken to milling the site and applying seeds of grass mixtures, and fertilizing to create the most optimal conditions for the fertile layer.

In the summer of 2018, monitoring studies were carried out for the presence of secondary salinization in the upland and wetland parts of the territory of the pilot industrial facility. The main agrochemical indicators characterizing soil fertility were determined (table 4).

Table 4. Agrochemical indicators of the soil of pilot industrial site No. 99 Novogodneye oil field one year after reclamation (monitoring).

\begin{tabular}{|c|c|c|c|c|}
\hline \multirow[b]{2}{*}{ Indicator } & \multicolumn{2}{|c|}{ The upland section } & \multicolumn{2}{|c|}{ The wetland section } \\
\hline & $\begin{array}{c}\text { Actual } \\
\text { value }\end{array}$ & Criterion & $\begin{array}{c}\text { Actual } \\
\text { value }\end{array}$ & Criterion \\
\hline $\mathrm{pH}$ salt extraction & 4.40 & $\begin{array}{l}\text { highly } \\
\text { acidic }\end{array}$ & 3.90 & $\begin{array}{l}\text { highly } \\
\text { acidic }\end{array}$ \\
\hline $\begin{array}{l}\text { Mass fraction of mobile phosphorus } \\
\left(\mathrm{P}_{2} \mathrm{O}_{5}\right), \mathrm{mg} \mathrm{kg}^{-1}\end{array}$ & 10.00 & very low & 10.0 & very low \\
\hline $\begin{array}{l}\text { Mass fraction of mobile potassium }\left(\mathrm{K}_{2} \mathrm{O}\right) \text {, } \\
\qquad \mathrm{mg} \mathrm{kg}^{-1}\end{array}$ & 24.00 & very low & 36.00 & very low \\
\hline Mass fraction of nitrate nitrogen, $\mathrm{mg} \mathrm{kg}^{-1}$ & less 2.80 & very low & less 2.80 & very low \\
\hline $\begin{array}{l}\text { Mass fraction of exchange calcium, } \\
\text { mmol } 100 \mathrm{~g}^{-1}\end{array}$ & 1.50 & very low & 2.50 & very low \\
\hline $\begin{array}{l}\text { Mass fraction of exchange magnesium, } \\
\text { mmol } 100 \mathrm{~g}^{-1}\end{array}$ & 1.00 & very low & 1.30 & average \\
\hline
\end{tabular}

It was noted that over the entire territory of the pilot industrial site, the values of the indicators of exchanged calcium, potassium, phosphorus, $\mathrm{pH}$ decreased. Therefore, additional agrotechnical and meliorative measures were carried out to improve the agrophysical and agrochemical properties of soils, which will improve grass cover. Macro and trace elements (nitrogen, magnesium, potassium, phosphorus) and lime were added to the soil at the rate of 5 tons per 1 ha. Additives were introduced over the entire area of the plot to a depth of $35 \mathrm{~cm}$. A month later the soils were sampled to determine the agrochemical parameters [16].

Based on the data obtained (table No. 5), the values of agrochemical indicators increased. This led to an improvement in the biochemical properties of soils in the whole territories of the pilot industrial.

High values of the indicators for the upper horizon in the wetland part of the pilot industrial site are associated with the presence of a peat layer with high sorption ability. Observation of the state of crops in field experiments showed good germination results, $85 \%$ of the plot was covered with grass cover (Figure 2). 
Table 5. Agrochemical indicators of the soil of the pilot industrial site after additional fertilizer application (in a month).

\begin{tabular}{|c|c|c|}
\hline Indicator & $\begin{array}{c}\text { The upland } \\
\text { section }\end{array}$ & The wetland section \\
\hline $\mathrm{pH}$ salt extraction & 7.50 & 7.10 \\
\hline Mass fraction of mobile phosphorus $\left(\mathrm{P}_{2} \mathrm{O}_{5}\right), \mathrm{mg} \mathrm{kg}^{-1}$ & 57.00 & 330.00 \\
\hline Mass fraction of mobile potassium $\left(\mathrm{K}_{2} \mathrm{O}\right), \mathrm{mg} \mathrm{kg}^{-1}$ & 131.00 & 484.00 \\
\hline Mass fraction of nitrate nitrogen, $\mathrm{mg} \mathrm{kg}^{-1}$ & less 2.80 & 21.90 \\
\hline Mass fraction of exchange calcium, mmol $100 \mathrm{~g}^{-1}$ & 6.00 & 7.00 \\
\hline Mass fraction of exchange magnesium, mmol $100 \mathrm{~g}^{-1}$ & 3.00 & 3.80 \\
\hline
\end{tabular}

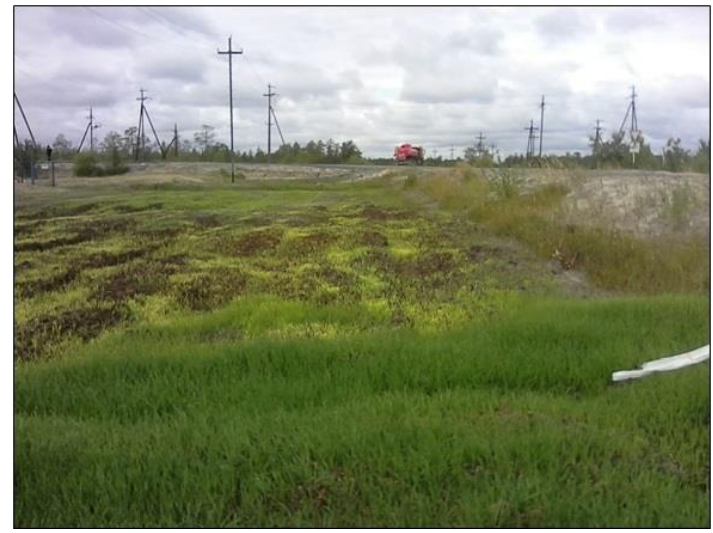

Fig. 2. Photo of the experimental plot №. 99 of the Novogodneye oil field of the Yamal-Nenets Autonomous District of the NNG Gazprom after reclamation.

\section{Conclusion}

To sum up, to make a conclusion that soil desalinization should be carried out in 2 stages (technical and biological) for 2 years when desalinating soils contaminated with oil and salt water in an oil field using an integrated approach.

In the first year, there should be created drainage channels and added the calciumcontaining reagents, depending on the agrochemical parameters of the soil, at the end of winter or in early spring. The introduction of salts (including in dissolved form) into the soil-adsorption complex will lead to the intensive melting of snow and the proceeding of exchange processes in the soil and it will restore exchange processes in the soil adsorption complex. After creating favorable conditions (oxygenation of the upper soil layer, application of mineral and nutrient fertilizers, maintaining optimal humidity, etc.), as well as stable positive summer temperatures, it is recommended that crops used for phytoreclamation in these areas are sown. In the second year, it is should be monitored the restored soils and add fertilizers containing macro and microelements (nitrogen, magnesium, potassium, phosphorus) to improve the agrophysical and agrochemical properties of the fertile soil layer.

Thus, a set of technical and technological solutions and land reclamation techniques based on the creation and formation of optimal conditions that can accelerate the processes of desalination and natural leaching. The data obtained can be used to restore soils contaminated with highly saline water in territories with a similar agrochemical composition. 


\section{Reference}

1 Oil and gas fields: Yamal-Nenets Autonomous Okrug - Russia - Oil and gas fields. Oil industry workers of the Russian Federation. Internet resource: http://www.nftn.ru/oilfields/russian_oilfields/jamalo_neneckij_ao/7

2 S. Jafarinejad, Oil-Spill Response Petroleum Waste Treatment and pollution control, 117-148 (2017) doi:10.1016/b978-0-12-809243-9.00004-3

3 I.C. Ossai, A. Ahmed, A. Hassan, F.S. Hamid, Environmental Technology \& Innovation, 17, 81 (2019) doi:10.1016/j.eti.2019.100526

4 D.M. Ward, T.D. Brock, Applied and Environmental Microbiology, 35, 353-359 (1978)

5 E. Rosenberg, E.Z. Ron, Bioremediation of petroleum contamination //Bioremediation: Principles and Applications, 100-124 (Cambridge University Press, UK, 1996)

6 J.T. Dibble, R. Bartha, Applied and Environmental Microbiology, 37, 729-739 (1979)

7 Government of the Yamal-Nenets Autonomous Okrug. https://www.yanao.ru/activity/2883/ (accessed: 12/9/2019)

8 E. Morillo, J. Villaverde, Science of The Total Environment, 586, 576-597 (2017) doi:10.1016/j.scitotenv.2017.02.020

9 S. Kuppusamy, P. Thavamani, K. Venkateswarlu, Y.B. Lee, R. Naidu, M. Megharaj, Chemosphere, 168, 944-968 (2017) doi:10.1016/j.chemosphere.2016.10.115

10 N.L. Karrick, Effects of Petroleum on Arctic and Subarctic Environments and Organisms, Nature and Fate of Petroleum, 1, 225-299 (1977)

11 D.M. Hamby, Science of The Total Environment, 191(3), 203-224 (1996) doi:10.1016/s0048-9697(96)05264-3

12 M. Megharaj, B. Ramakrishnan, K. Venkateswarlu, N. Sethunathan, R. Naidu, Environment International, 37(8), 1362-1375 (2011) doi:10.1016/j.envint.2011.06.003

13 S.K. Samanta, O.V. Singh, R.K. Jain, Trends in Biotechnology, 20(6), 243-248 (2002) doi:10.1016/s0167-7799(02)01943-1

14 S. Wyke, A. Peña-Fernández, N. Brooke, R. Duarte-Davidson, Environment International, 72, 109-118 (2014) doi:10.1016/j.envint.2014.05.002

15 P- Morgan, FEMS Microbiology Letters, 63(4), 277-300 (1989) doi:10.1016/03781097(89)90398-4

16 F.I. Khan, T. Husain, R. Hejazi, Journal of Environmental Management, 71(2), 95122 (2004) doi:10.1016/j.jenvman.2004.02.003 